\title{
OCORRÊNCIA DE MASTITE BOVINA EM FAZENDAS PRODUTORAS DE LEITE B NO ESTADO DE SÃO PAULO
}

\author{
L.F. LARANJA \\ Faculdade de Medicina Veterinaria e Zootecnia/USP, C.P. 23, CEP: 13630-000 - Pirassununga,SP \\ P.F. MACHADO \\ Departamento de Zoologia-ESALQ/USP, C.P. 9, CEP: 13418-900 - Piracicaba,SP
}

\begin{abstract}
RESUMO: Durante o período compreendido entre os meses de Março/1991 e Fevereiro /1992 foi realizado um experimento com o objetivo de avaliar a prevaléncia da mastite bovina em 07 fazendas produtoras de leite tipo B de diferentes regiões do estado de São Paulo. Foram analisadas 1683 vacas que deram origem a 7695 resultados do CMT e das quais foram coletadas 983 amostras de leite para realização do exame microbiologico. A análise do CMT indicou 47,0\% de vacas com CMT negativo, 15,1\% CMT + e 37,5\% CMT $++1+++$. Os escores do CMT foram distribuidos segundo o número de lactação (1* lactação, $2^{*}$ lactação e $3^{*}$ ou + lactaç̃es) e segundo o estágio de lactação (1-30 dias de lactação, 31-90 dias, 91-250 dias e $>250$ dias). A análise dos dados demonstrou que houve um efeito significativo ( $p<0,0001$ ) tanto do número quanto do estágio de lactação sobre a \% de vacas $\mathrm{CMT}++/+++$. Com relação ao perfil microbiologico das fazendas estudadas, foram encontradas $501(50,97 \%)$ amostras positivas de um total de 983 amostras avaliadas. Das amostras positivas, destacou-se o Staphylococcus sp $(44,6 \%)$ seguido por Corynebacterium sp $(15,0 \%)$, Streptococcus sp $(8,2 \%)$. Leveduras/Fungos $(5,4 \%)$, Bacillus sp $(4,4 \%)$, E.coli $(3,2 \%)$ e Klebsiella sp (0,2\%). Se considerarmos o isolamento tanto em cultura pura quanto em cultura mista, a ocorrência de Staphylococcus sp passa para 55,6\%, a de Corynebacterium sp para 18,6\% e a Streptococcus sp para 15,0\%. Descritores: mastite, prevalência, CMT, microbiologia
\end{abstract}

\section{OCCURRENCE OF BOVINE MASTITIS IN GRADE B MILK FARMS IN THE STATE OF SÃO PAULO}

\begin{abstract}
SUMMARY: From March/1991 to February/1992 1,683 cows from seven grade "B" milk producing dairy farms were used in a study on the prevalence of bovine mastitis. CMT tests $(7,695)$ were $47.0 \%$ negative; $15.1 \%$ " + and $37.5 \% "++1+++"$. CMT scores were grouped by number of lactation (1st, 2nd, 3rd or more) and by stage of lactation (1-30 days in milk; 31-90 days; $91-250$ and $>250$ days). Both stage of lactation and number of lactation had significant effect on \% of cows CMT $n+1+++n$. Microbiological results from 983 milk samples were $50.97 \%$ positive. From the positive samples were isolated Staphylococcus sp (44.6\%), Corynebacterium sp (15.0\%), Streptococcus sp (8.2\%), Yeast/Fungi (5.4\%). Bacillus sp (4.4\%), E. coli (3.2\%) and Klebsiella sp (0.2\%). Considering both pure and mixed culture isolation, Slaphylococcus sp represents $55.6 \%$, Corynebacterium $\mathrm{sp}, 18.6 \%$ and Streptococcus sp, $15.0 \%$.
\end{abstract}

Key Words: mastitis, prevalence, CMT, microbiology

\section{INTRODUÇÃO}

A mastite bovina tem sido apontada como a principal doença que afeta os rebanhos leiteiros no mundo inteiro, causando sérios prejuízos econômicos tanto ao produtor de leite quanto à indústria de laticínios. Estima-se que nos EUA haja uma perda da ordem de 02 bilhões de dólares/ano somente em decorrência da doença (National Mastitis Council, 1987).

No Brasil não se dispõe até o momento de estimativa de prejuízos econômicos causados pela mastite, no entanto, alguns estudos apontam uma alta prevalência da doença. LANGENEGGER et al. (1970) examinando 2187 vacas através do CMT encontraram que 429 (20\%) apresentavam reação positiva ao CMT. Já NADER FILHO et al. (1983) estudando 468 vacas pertencentes a 6 rebanhos leiteiros da região de Barretos, encontraram 56 animais $(11,97 \%)$ positivos ao CMT.

Cabe ressaltar que devido à limitação dos métodos diagnósticos existentes no Brasil, um certo cuidado deve ser observado para se comparar os resultados dos diferentes trabalhos de levantamento de mastite realizados visto que a grande maioria desses trabalhos utilizou o CMT 
como parâmetro de avaliação, teste esse que envolve certo grau de subjetividade de análise.

Com relação ao perfil microbiológico dos rebanhos, vários trabalhos têm apontado que o Staphylococcus sp $€$ o principal agente causador de mastite no Brasil. LANGENEGGER et al. (1970) encontraram $53,1 \%$ de S.aureus dentre 429 vacas com exame microbiológico positivo. Nesse estudo também foram isolados S.agalactiae $(24,7 \%), S$. dysgalactiae $(17,2 \%)$ e $S$. uberis $(4,6 \%)$. NADER FILHO et al. (1983) encontraram dentre as amostras positivas obtidas $52,08 \%$ de S.aureus, $14,58 \%$ de S.dysgalactiae, $10,42 \%$ de S.agalactiae, $8,33 \%$ de S.uberis e $6,25 \%$ de S.epidermidis. LANGONI et al. (1990) examinando 702 amostras de leite com mastite subclínica encontraram a seguinte ocorrência de agentes: S.aureus $36,9 \%$, S.epidermidis $22,2 \%$, C.bovis $4,8 \%$. C.pyogenes $4,4 \%$, S.uberis $4,3 \%$, E.coli $4,0 \%$, S.dysgalactaie $3,8 \%$, S.agalactiae $3,7 \%$ e Candida albicans $3,8 \%$. Cabe ressaltar o aumento na importância do C.bovis como agente etiológico causador de mastite observado em trabalhos de levantamento mais recentes. COSTA et al. (1985) isolaram C. bovis em 954 amostras $(32,50 \%)$ de um total de 2.935 oriundas de 17 municípios do Estado de São Paulo. Este trabalho reforça a tendência verificada que aponta o C.bovis como segundo agente em termos de freqüência de isolamento em trabalhos realizados no Brasil.

Desta forma, o objetivo deste trabalho é contribuir com dados sobre a prevalência da mastite bovina em fazendas produtoras de leite B no Estado de São Paulo através da realização do CMT e do exame microbiológico de leite.

\section{MATERIAL E MÉTODOS}

O trabalho experimental, a nível de campo, foi realizado em rebanhos pertencentes a 07 municípios do Estado de São Paulo (Piracicaba, Campinas, Itu, Assis, Engenheiro Coelho, Descalvado e São Roque).

As análises microbiológicas de leite foram realizadas no Laboratório de Doenças Infecciosas da Faculdade de Medicina Veterinária e Zootecnia da Universidade de São Paulo.

O período experimental compreendeu os meses entre Março de 1991 e Fevereiro de 1992. Foram analisadas 1.683 vacas que deram origem a 7.695 resultados do CMT e das quais foram coletadas 983 amostras para exame microbiológico.
Foram utilizadas para execução do trabalho 06 rebanhos comerciais produtores de leite tipo B e considerados de destaque no Estado de São Paulo e o rebanho experimental do Departamento de Zootecnia da ESALQ. Os rebanhos eram compostos predominantemente por animais da raça Holandesa (PO, POI e PC) com médias de produção variando entre 15 e 26 litros/vaca lact./dia.

O CMT foi realizado durante todas as visitas feitas às fazendas, em todas as vacas $\mathrm{em}$ lactação do rebanho. O procedimento adotado foi baseado na metodologia de SCHALM \& NOORLANDER (1957), isto é, procedeu-se a retirada dos primeiros jatos de leite antes da ordenha, desprezando-os, e colhendo-se logo após $2 \mathrm{ml}$ de leite de cada teto nos respectivos recipientes da bandeja de CMT, adicionou-se então, $2 \mathrm{ml}$ da solução CMT (produto comercial marca FATEC) e agitou-se a mistura por 10-15 segundos, procedendo-se então imediatamente a leitura do teste.

As reações foram classificadas da seguinte maneira:

NEGATIVO (n) = sem formação de gel.

$1+(+)=$ leve formação de gel.

$2+(++)=$ formação de gel espesso bem definido

$3+(+++)=$ gel bastante espesso, assentando no fundo da bandeja.

Foram coletadas amostras de leite para exame microbiológico de todas as fazendas envolvidas no trabalho com a finalidade de avaliar o perfil microbiológico do rebanho. As coletas foram feitas numa distribuição aleatória entre os animais em lactação e envolveu no mínimo $18 \%$ do rebanho total da fazenda, sendo que em duas fazendas foi realizada a coleta de $100 \%$ das vacas em lactação.

Coleta de amostras de leite: As amostras de leite para exame microbiológico foram coletadas em tubos de ensaio de forma asséptica.

O procedimento para coleta constou da limpeza dos tetos com solução desinfetante a base de Iodo (solução de pré-dipping) e secagem com toalha de papel descartável. Essa limpeza era precedida pela retirada e descarte dos primeiros jatos de leite. Logo após era feito a desinfecção da extremidade posterior do teto e esfincter do teto com algodão embebido em álcool $70 \%$.

As amostras coletadas foram compostas, isto $e$, foram coletadas amostras dos quatro tetos de cada animal em um único frasco. Dessa forma 
eram retiradas quantidades semelhantes de cada um dos tetos de maneira a totalizar aproximadamente $10 \mathrm{ml}$ de leite por amostra composta.

Após a coleta, as amostras eram refrigeradas e encaminhadas ao laboratório de Doenças Infecciosas da Faculdade de Medicina Veterinária e Zootecnia da Universidade de São Paulo.

Foi utilizado o teste de Qui-Quadrado em nível de significância de $1 \%$ para avaliar as diferenças entre os percentuais de vacas CMT $++1+++$ nos diferentes estágios e números de lactação. Os efeitos de Fazenda, Estágio e Número de Lactação e suas interações sobre a variável diagnóstico (CMT) foram processados através do PROC CATMOD do SAS (1985).

\section{RESULTADOS E DISCUSSÃO}

\section{* Prevalência de mastite}

Na TABELA 1 encontram-se os dados de CMT obtidos em cada fazenda. $O$ valor médio, incluindo todas as fazendas estudadas, relativo a \% DE VACAS CMT $++1+++$ foi de $37,9 \%$. Esse coeficiente variou de forma significativa entre as fazendas, sendo que a fazenda 01 apresentou o valor de $14,4 \%$ de VACAS CMT $++1+++$ enquanto que na fazenda 07 esse coeficiente foi de $58.8 \%$. Se compararmos com outros trabalhos já realizados, este experimento apontou uma alta Contagem de Células Somáticas (CCS) nas fazendas estudadas. NADER FILHO et al. (1983) analisando 468 vacas em 06 fazendas encontrou 9,4\% com CMT positivo e $2,58 \%$ com CMT suspeito, sendo que a fazenda com o maior valor apresentou $16,66 \%$ e $7,14 \%$ de vacas CMT positivo e suspeito respectivamente enquanto que a fazenda com o menor coeficiente apresentou esses valores na ordem de $4,65 \%$ e $3,49 \%$. LANGENEGGER et al. (1970) analisando 2.187 vacas encontraram $20 \%$ com CMT positivo. Entendemos que é importante destacar que existe uma certa dificuldade em comparar resultados baseados no CMT em função da alta subjetividade que envolve esse teste.

$\mathrm{Na}$ TABELA 2 encontram-se os percentuais de ocorrência de cada escore do CMT em função do número de lactação. Nessa TABELA pode-se observar que a porcentagem de VACAS CMT $++1+++$ aumenta de forma significativa ( $p$ $<0,01)$ com o avanço no número de lactação, sendo que esse coeficiente é de $21,5 \%$ para a primeira lactação, $42,0 \%$ para a segunda lactação e $54,8 \%$ para a terceira lactação.

A TABELA 3 apresenta a distribuição dos escores do CMT em função do estágio de lactação. Pode-se observar que a porcentagem VACAS CMT $++1+++$ aumenta lentamente do início para o final da lactação. No estágio I (1-30 dias) esse coeficiente apresenta o valor de $29,9 \%$, no estágio II ( $31-90$ dias) de $35,2 \%$, no estágio III (91-250 dias) de $38,3 \%$ e no estágio IV de $41,8 \%$. Pode-se observar nessa tabela que não há diferença significativa $(p<0,01)$ entre os estágios I e II, II e III, III e IV. No entanto a diferença é significativa entre os estágios I e III, II e IV.

Portanto, pelos resultados obtidos ficou evidente um forte impacto do número de lactação sobre a CCS. Já com relação ao estágio de lactação esse efeito não foi tão acentuado. Cabe ressaltar que não foi considerado neste trabalho a origem da variação na $\mathrm{CCS}$ em função do número e estágio de lactação, isto $\varepsilon$, não foi avaliado se esse aumento na CCS foi devido ao aumento na prevalência da infecção com o passar do tempo ou se foi um aumento fisiológico sem aumento no nível de infecção. Muito trabalhos foram realizados com o objetivo de avaliar esta matéria, e os resultados muitas vezes são discordantes em relação as causas e em níveis de variação na CCS com o aumento no número e estágio de lactação, mas é praticamente unânime que esse aumento ocorre.

PHILPOT (1986) e NICKERSON (1986) afirmaram que o aumento na CCS ocorre tanto em função da idade quanto em função do estágio de lactação e isso se deve provavelmente ao aumento na prevalência de mastite subclínica com o passar do tempo e não devido ao estágio de lactação e idade por si só apesar de que PHILPOT (1986) ressalta que mesmo na ausência de infecção há um aumento da CCS em função da idade.

Vários pesquisadores demostraram que a CCS dos animais mais jovens não aumenta de forma tão significativa quanto a dos animais mais velhos no final da lactação (BODOH et al., 1976; TIMMS \& SCHULTZ, 1987 e PHILPOT \& NICKERSON, 1986). Já WIGGANS \& SHOOK (1987) fazendo uma revisão sobre o assunto citaram que investigações realizadas sobre os fatores ambientais que afetam a CCS têm mostrado que rebanho, vaca, ano, estágio de lactação, época do ano e idade da amostra são importantes fontes de variação. $O$ estágio de lactação e a época do ano também são fontes de variação para a incidência de infecção do úbere. 


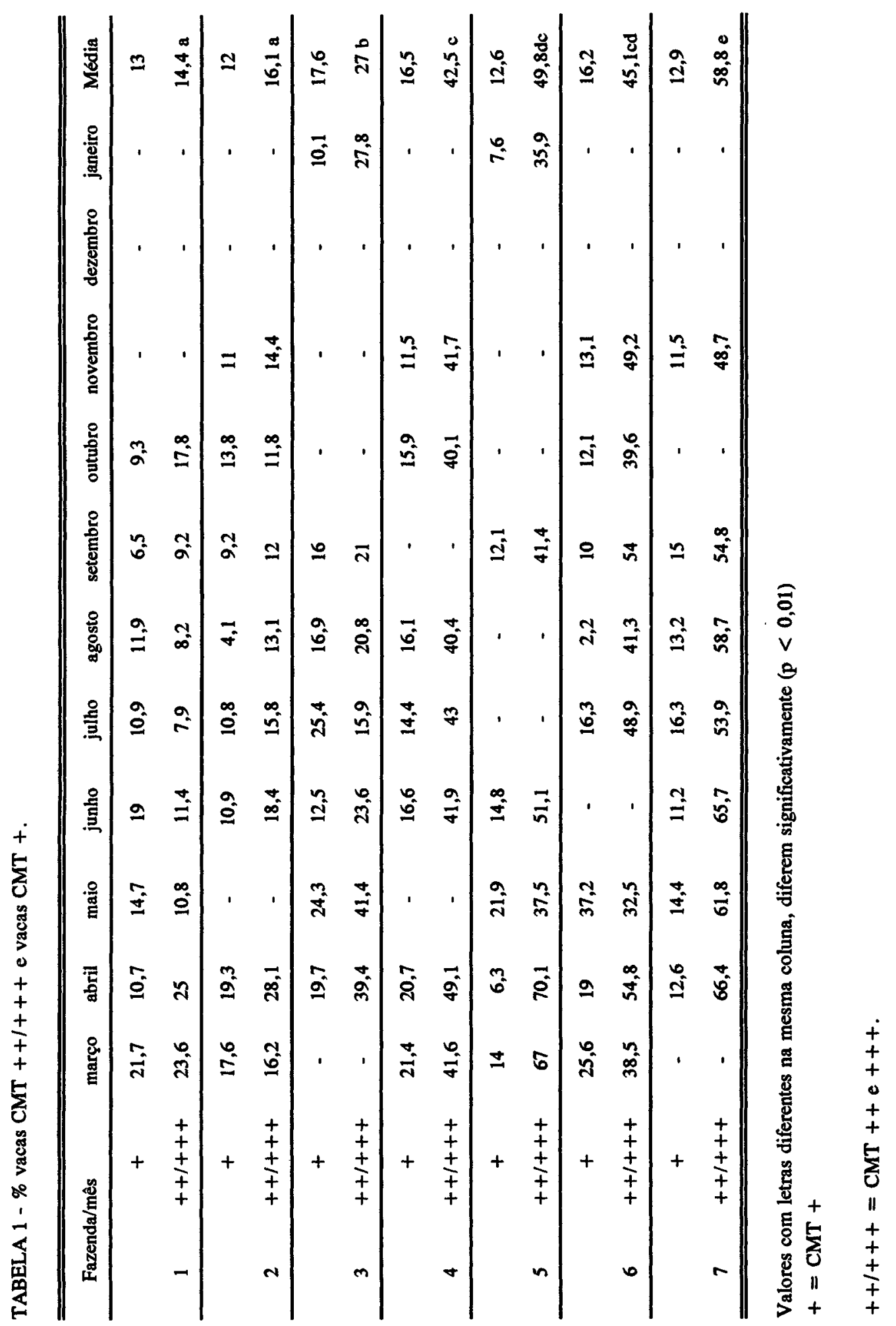



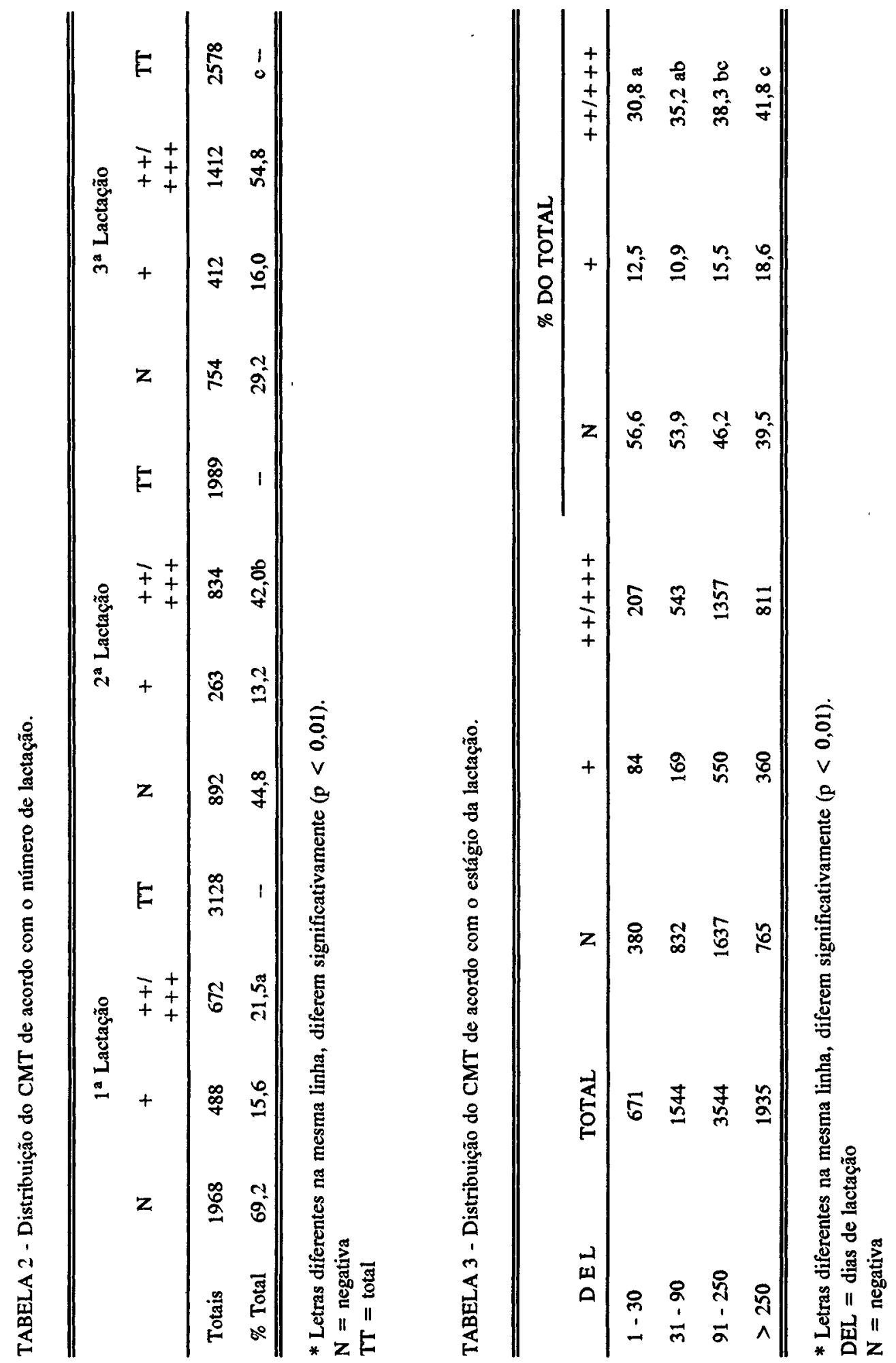

Sci. agric., Piracicaba, 51(3):578-585, set./dez. 1994 


\section{* Patógenos x CMT e número de lactação}

Analisando os resultados do CMT (TABELA 4), pode-se calcular que os escores $\mathrm{N}$, ,$+++\mathrm{e}+++$ apresentaram $57,8 \%, 43,2 \%$, $37,7 \%$ e $30,4 \%$ das amostras com resultados negativos. $O$ perfil do resultado é lógico, pois a medida que aumenta a contagem celular aumenta a porcentagem de agentes isolados, no entanto, cabe ressaltar que mesmo dentre as amostras oriundas de vacas CMT negativo houve isolamento de agentes em $42,2 \%$ das mesmas. No outro extemo, ou seja, dentre os exames oriundos de vacas com CMT +++ , não houve isolamento $\mathrm{em} 30,4 \%$ das amostras. $O$ isolamento de agentes em uma grande proporção de vacas com CMT negativo pode ser explicado pelo fato de que o CMT não é um teste muito sensivel no seu limite inferior, ou seja, para baixas CCS. Ressaltamos também que neste trabalho não foi utilizado o escore Traços e que portanto, alguns animais que teriam sido classificados com esse escore, na verdade foram considerados negativos. Assim, os animais CMT negativo podem apresentar até $500.000 \mathrm{cé} / \mathrm{ml}$, sendo que esse é um limite que dá margem a presença de uma infecção. Além disso, sabemos que certos patógenos específicos tais como Corynebacterium bovis e Staphylococcus coagulase negativo tem a característica de determinar uma baixa resposta celular do hospedeiro. Entendemos que deve-se considerar ainda a possibilidade de isolamento de agentes na fase inicial do processo infeccioso, fase essa em que ainda não houve aumento efetivo da contagem celular do leite do animal infectado. Em relação à grande proporção de animais com $\mathrm{CMT}+++$ que não tiveram nenhum agente isolado, pode-se dizer que esse achado já era esperado. Isso se justifica em função de que animais que apresentam uma contagem celular alta também apresentam uma alta taxa de fagocitose, fato esse que pode determinar a presença de poucos patógenos viáveis no leite. Além disso, muitas vezes, após o fim do processo infeccioso, a CCS permanece alta, sendo que esse período sem a presença de patogenos e alta contagem celular pode durar até vários meses, principalmente em casos de mastite causada por S.aureus (DINSMORE et al., 1992).

Na TABELA 5 encontra-se a distribuição dos patógenos isolados em função do número de lactação. Nessa tabela observa-se que não há um aumento na porcentagem de vacas infectadas com o aumento no número de lactação, sendo que a porcentagem de vacas com exame microbiológico positivo foi de $66,4 \%$ para animais de primeira lactação, $62,3 \%$ para vacas de segunda lactação e $71,3 \%$ para animais de terceira lactação ou mais. Destacamos também, nessa tabela, a alta porcentagem de novilhas de primeira lactação infecta-das com Staphylococcus sp, valor esse de $44,1 \%$, enquanto as vacas de segunda e terceira lactação apresentaram valores de $30,0 \%$ e $25,9 \%$ respectivamente. Visto que a expectativa era de que a porcentagem de vacas infectadas com Staphylococcus sp aumentasse com o avanço no número de lactação, ressaltamos que esses resultados encontrados têm uma forte influência de uma fazenda isolada (Fazenda 5) que apresentava altas taxas de infecções por Staphylococcus sp em novilhas e que foi justamente a fazenda que contribuiu com o maior número de exames microbiológicos individualmente. Apesar disso, vários trabalhos de pesquisa têm mostrado a alta prevalência de Staphylococcus sp. em animais de primeira lactação.

PANKEY (1990) avaliou a prevalência de mastite em novilhas de 1 lactação. Foram analisadas 382 novilhas oriundas de 11 fazendas do estado de Vermont. Os resultados mostraram que $45,5 \%$ das novilhas e $18,7 \%$ dos quartos apresentavam infecção intramamária após a parição. Esses resultados indicaram uma prevalência menor de infeç̧ões quando comparados com os trabalhos realizados por OLIVER \& MITCHEL (1984), no Tennessee e por TRINIDAD et al (1990) em Lousiana, que encontraram resultados de $64 \%$ e $98 \%$ respectivamente.

Dentre as infecções encontradas, o Staphylococcus sp foi o mais prevalente, sendo isolado em $23 \%$ das novilhas e $11 \%$ dos quartos, seguido por patógenos ambientais $(15 \%$ das novilhas e $5 \%$ dos quartos), S.aureus $(2,6 \%$ das novilhas e $0,7 \%$ dos quartos). Os patógenos maiores foram encontrados em $22,7 \%$ das novilhas e $7,2 \%$ dos quartos, e o autor concluiu que este nível deveria ser considerado um problema de rebanho, e indica a necessidade de monitorar o "status" de infecção dentro de cada rebanho para avaliar a efetividade do programa de reposição de animais jovens.

\section{CONCLUSÕES}

1- A prevalência de mastite subclínica, avaliada através da utilização do CMT, apresentou-se bastante alta em fazendas produtoras de leite $B$ e consideradas de destaque no Estado de São Paulo. 
OCORRÊNCIA DE MASTITE BOVINA EM FAZENDAS PRODUTORAS DE LEITE B ...

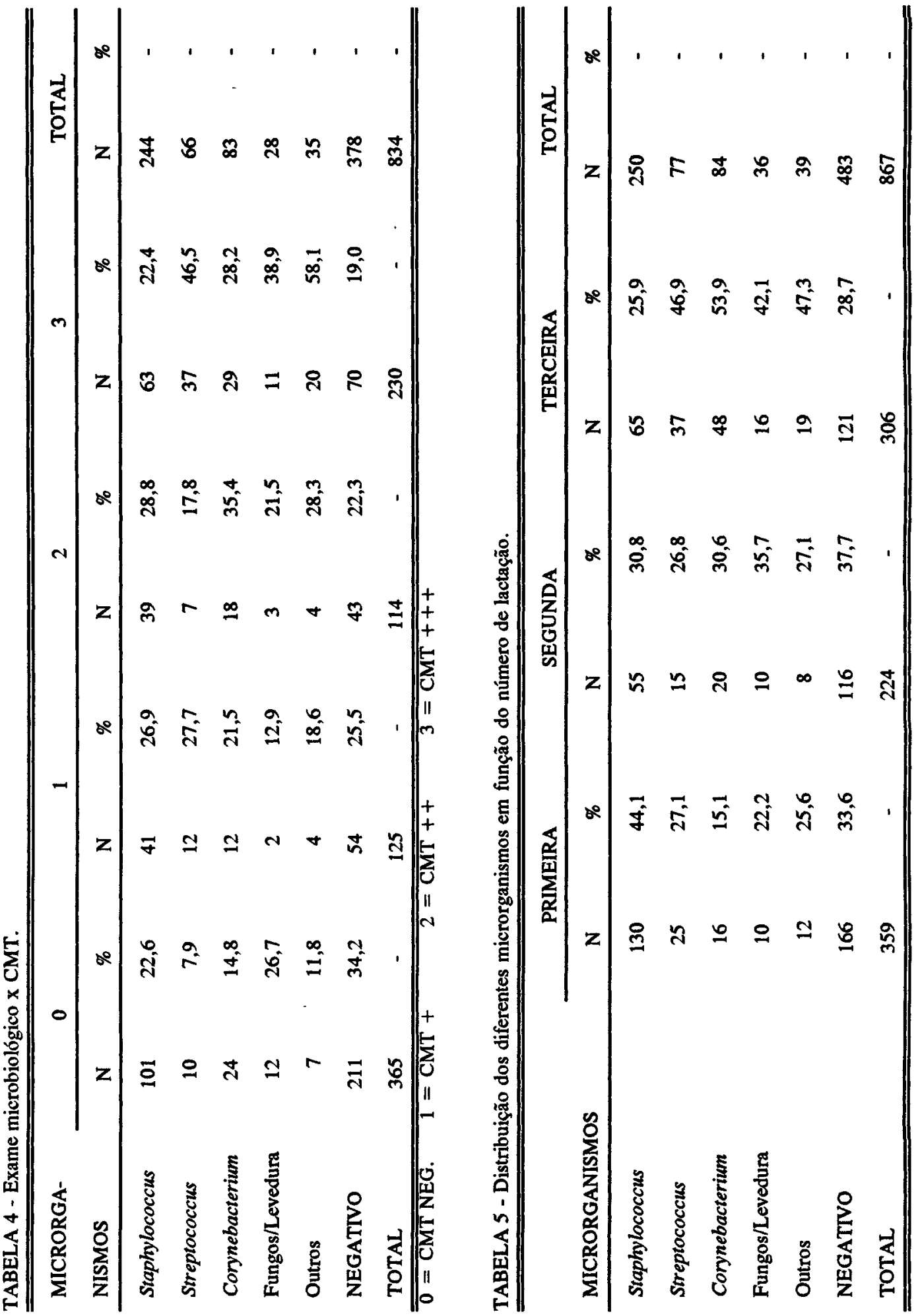

Sci. agric., Piracicaba, 51(3):578-585, set./dez. 1994 
2- $O$ agente infeccioso isolado com maior frequência foi o Staphylococcus sp destacando-se em $2^{\circ}$ lugar o Corynebacterium sp confirmando a sua crescente importância dentre os agentes etiologicos causadores de mastite no Estado de São Paulo.

3- O CMT mostrou-se um bom instrumento de avaliação do "status" de mastite dos rebanhos, no entanto, testes mais precisos de avaliação da CCS auxiliariam de forma significativa no diagn6stico de situação das fazendas e eliminariam a subjetividade caracterísitca do CMT.

4- Foi observado um efeito significativo do número de lactação e um pequeno efeito do estágio de lactação sobre o coeficiente porcentagem VACAS CMT $++l+++$. Cabe ressaltar que não foram analisadas as causas que levaram a esse aumento na contagem celular em função do número e está-

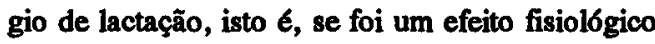
ou um efeito das infecçoes intramamárias.

5- Destacou-se a grande proporção de animais de primeira lactação que apresentaram exame microbiológico positivo, especialmente com isolamento de Staphylococcus sp, o que confirma várias pesquisas recentes e aponta para a necessidade de estudos envolvendo epidemiologia e medidas de controle efetivas em nível de fazenda.

6- A alta prevalência de microorganismos patogênicos causadores de mastite contagiosa tais como Staphylococcus sp, sugere que essa seja a forma de mastite mais importante nos rebanhos avaliados e indica deficiência nas práticas de manejo, higiene e terapêtica nas fazendas estudadas.

\section{REFERENCIAS BIBLIOGRÁFICAS}

BODOH, G.W.; BATTSTA, W.J.; SCHUTZ, L.H.; JOHNSTON, R.P. Variation in somatic cell counts in Dairy Herd Improvement milk samples. Journal of Dairy Science, Champaign, v.59, p.1119, 1976.

COSTA, E.O.; CARVALHO, V.M.; COUTINHO, S.D.; CASTILHO, W; CARAMORE, L.F.L. Corynebacterium bovis e sua importância na etiologia da mastite bovina no Estado de São Paulo. Pesquisa Veterinaria Brasileira, Brasilia, v.5, n.4, p.117-120, 1985.

DINSMORE, R.P.; ENGLISH, P.B.; GONZALES, R.N.; SEARS, P.M. Use of augmented cultural techniques in the diagnosis of the bacterial cause of clinical bovine mastitis. Joumal of Dairy Science, Champaign, n.75, p.2712, 1992.
LANGENEGGER, H.; COELHO, N.M.; HANGENEGGER, C.H.; CASTRO, R.P. Estudo da incidencia da mastite bovina na bacia leiteira do Rio de Janeiro. Pesquisa Agropecuaria Brasileira, Brasilia, v.5, p.437, 1970.

LANGONI, H.; PINTO, M.P.; DOMINGUES, P.F.; LISTONI, FJ.P. Mastite bovina subclínica: etiologia e sensibilidade bacteriana. Comunicacåno Cientifica da Faculdade de Medicina Veterinaria e Zootecnia, Pirassununga, v.14, n.1, p.11-31, 1990.

NADER FILHO, A.; SHOCKEN-ITURRINO, R.P.; ROSSI Jr., O.D. Mastite subclínica em rebanhos produtores de leite tipo B. Arquivo Brasileiro de Medicina Veterinaria e Zootecnia, Belo Horizonte, v.35, n.5, p.621-630, 1983.

NATIONAL MASTITIS COUNCIL. Current Concepts on Bovine Mastitis. 3.ed. Arlington, 1987. p.5-46.

NICKERSON, s.C. Mastitis Control. Baton Rouge: Louisiana Agricultural Experiment Station, 1986. p.1-7.

OLIVER, S.P.; MTCHELL, B.A. Prevalence of mastitis pathogens in herds participating in a mastitis control program. Journal of Dairy Science, Champaign, n.67, p.2436, 1984.

PANKEY, J.W. Problem solving - an academic approch. In: INTERNATIONAL SYMPOSIUM ON BOVINE MASTITIS, Indianapolis, 1990, Indianápolis: AABP/NMC, 1990. p.388-393.

PHILPOT, W.N.; NICKERSON, S.C. Quality millk production and mastitis control. Baton Rouge: Louisiana Agricultural Experiment Station, 1986. p.8-47.

PHILPOT, W.N. Somatic cell counts and your mastitis control program. Baton Rouge: Louisiana Agricultural Experiment Station, 1986. p.48-57.

SAS. User's guide. 5.ed. Cary, 1985.

SCHALM, O.W.; NOORLANDER, D.O. Experiments and observations leading to development of California Mastitis Test. Journal of the American Veterinary Medical Association, Ithaca, n.130, p.199-204, 1957.

TIMMS, L.L.; SCHULTZ, L.H. Dynamics and significance of coagulase-negative Staphylococcal infections. Jourmal of Dairy Science, Champaign, n.70, p.2648, 1987.

TRINIDAD, P.; NICKERSON, P.C.; ALLEY, T.K. Prevalence of intramammary infection and teat canal colonization in unbred and primigravid dairy heifers. Journal of Dairy Science, Champaign, n.73, p.107, 1990.

WIGGANS, G.R.; SHOOK, G.E. A lactation measure of somatic cell count. Journal of Dairy Science, Champaign, n.70, p.2666, 1987.

Enviado para publicação em 21.01.93

Aceito para publicaçáo em 30.06.94 